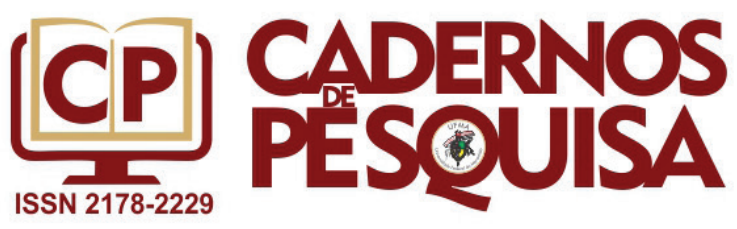

ISSN 2178-2229

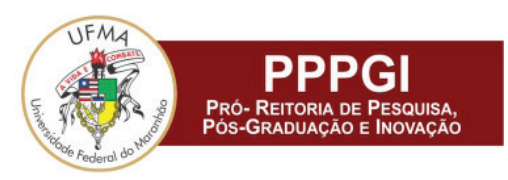

DOl: $h t t p: / / d x . d o i . o r g / 10.18764 / 2178-2229 . v 26 n 2 p 217-236$

\title{
PRODUÇÃO DO CONHECIMENTO CIENTÍFICO EM EXTENSÃO \\ UNIVERSITÁRIA: uma análise bibliométrica do cenário nacional
}

\author{
PRODUCTION OF SCIENTIFIC KNOWLEDGE IN UNIVERSITY EXTENSION \\ PROGRAMS: a bibliometric analysis of the national scenery \\ PRODUCCIÓN DEL CONOCIMIENTO CIENTÍFICO EN EXTENSIÓN \\ UNIVERSITARIA: um análisis bibliométrico del escenario nacional
}

\author{
Vania Silva de Souza Bilert \\ Professora Doutora da Universidade Estadual do Centro-Oeste - UNCENTRO. \\ vaniabilert@hotmail.com \\ Cristiane Mansur de Moraes Souza \\ Professora Doutora da Universidade Regional de Blumenau - FURB \\ arqcmansur@gmail.com
}

\begin{abstract}
Resumo
O objetivo deste trabalho foi analisar a produção científica em Extensão Universitária proveniente das publicações nacionais de teses, dissertações e periódicos, no período de 2007 a 2016 . O estudo investigativo foi orientado pelo desenho metodológico da análise bibliométrica em caráter exploratório. As informações foram extraídas da base de dados da Coordenação de Aperfeiçoamento de Pessoal de Nível Superior (CAPES). Após aplicação dos filtros de pesquisa, os resultados mostraram 535 teses e dissertações e 227 artigos completos que foram analisados e classificados para atingir o objetivo proposto. Os resultados encontrados sugerem um crescimento do volume de publicações a partir de 2009 , com o delineamento metodológico na modalidade de estudo de caso. Verificou-se uma maior concentração nas áreas temáticas de saúde e educação. Já, em relação aos enfoques das pesquisas, observou-se o predomínio dos seguintes assuntos: saúde coletiva, formação de estudantes, formação docente e institucionalização da extensão. Os achados também indicam que os autores mais produtivos concentram suas pesquisas no enfoque de saúde coletiva e estão vinculados à Universidade de São Paulo - USP.
\end{abstract}

Palavras-chave: Universidade. Extensão universitária. Análise bibliométrica.

\begin{abstract}
The objective of this work was to analyze the scientific production in University Extension, from the national publications of theses, dissertations and periodicals, from 2007 to 2016. This investigative research of exploratory nature was guided by the methodological design of bibliometric analysis. Thus, information was extracted from CAPES' (Coordination of Superior Level Staff Improvement) database. Having conducted a research on CAPES' website, 535 dissertations and theses were found, along with 227 complete articles. The data was analyzed and classified in order to accomplish our study's main goal. Our results suggest the increase in the number of publications since 2009, with methodological delineation of case study type. It was observed that most studies were concentrated in Health and Education fields. As for the research studies' foci, predominance was perceived in the following issues: Collective Health, Formation of Students and Formation of Teachers, as well as Extension Programs Institutionalization. Our findings also indicate that authors, who produce the most, concentrate their studies - in their entirety - in Collective Health, and are also bound by USP (University of São Paulo).
\end{abstract}

Keywords: University. University Extension Programs. Bibliometric Analysis.

\section{Resumen}

El objetivo en este trabajo fue analizar la producción científica en Extensión Universitaria, proveniente de las publicaciones nacionales de tesis, disertaciones y periódicos, en el período de 2007 a 2016 . El estudio

Artigo recebido em março de 2018. Aprovado em junho de 2019.

Cad. Pesq., v. 26, n. 2, abr./jun., 2019. 
investigativo fue orientado por el dibujo metodológico del análisis bibliométrico, de carácter exploratorio. Las informaciones fueron extraídas de la base de datos de la Coordenação de Aperfeiçoamento de Pessoal de Nível Superior (CAPES). Tras los filtros de investigación, los resultados mostraron 535 tesis y disertaciones y 227 artículos completos, que fueron analizados y clasificados para atingir el objetivo de ese estudio. Los resultados encontrados sugieren un crecimiento del volumen de publicaciones a partir de 2009, con el delineamiento metodológico en la modalidad de estudio de caso. Se verificó una más grande concentración de estudios en las áreas temáticas de Salud y de la Educación. Ya, con relación a los enfoques de las investigaciones, se observó el predominio de los siguientes asuntos: Salud Colectiva, Formación de Estudiantes, Formación Docente e Institucionalización de la Extensión. Los hallazgos también indican que los autores más productivos concentran la totalidad de sus investigaciones con enfoques acerca de la Salud Colectiva y están vinculados a la Universidade de São Paulo - USP.

Palabras clave: Universidad. Extensión universitaria. Análisis bibliométrico.

\section{INTRODUÇÃO}

A universidade enfrentou longos e múltiplos desafios desde sua criação. Muitos deles foram provenientes do processo de definição de seus objetivos e da organização acadêmica, ou seja, da constituição de sua identidade. Outros desafios foram pautados no sentido de responder às demandas e às transformações sociais, influenciadas e referenciadas pela sua articulação com a sociedade. Tais perspectivas permearam durante décadas com modelos universitários estreitos, em que prevaleceu o princípio dos dois elementos: ensino e pesquisa.

Com a reorientação da função social da universidade, a partir da década de 1980, iniciaram-se os amplos debates sobre a necessidade de efetivar os eixos para a aproximação entre universidade e sociedade (ROCHA, 2001). Propunha-se, assim, a criação de um terceiro elemento que, associado ao ensino e à pesquisa, efetivaria a gênese da indissociabilidade entre ensino, pesquisa e extensão. Esse cenário trouxe para o debate a essência de que os elementos fundamentais e determinantes para o processo de reorientação do sistema centralizado, bem como a instrumentalização da universidade, só seriam concretizadas com a articulação profunda entre a prática educativa e o contexto social.

Tal perspectiva enfatiza o papel da extensão universitária e define-a como um "[...] processo educativo, cultural e científico que articula o ensino e a pesquisa e viabiliza a relação transformadora entre a universidade e a sociedade" (FORPROEX, 2000, p. 5). Observa-se que a proposta de extensão universitária busca englobar e enfatizar a construção de quadros que internalizam questões sociais e de políticas públicas.

No entanto, apesar das efervescentes discussões sobre o espaço da extensão universitária, suas relações ainda se esbarram na construção de marcos legais e de diretrizes, podendo ser considerada um processo ainda em construção. Nesse sentido, este estudo está centrado em trazer elementos para fomentar as discussões sobre a produção científica em extensão universitária e em vislumbrar uma forma de repensar o papel da extensão universitária e sua organicidade. Ademais, acredita-se que, para compreender o contexto e a perspectiva das ações de extensão universitária, torna-se útil apresentar um estudo bibliométrico com levantamentos e mapeamentos de suas principais características, trajetórias e tendências.

Compreende-se que um estudo dessa natureza contribuirá para trazer elementos subjacentes e capazes de fazer repensar o novo delineamento da extensão universitária, além de destacar como ela vem sendo integrada e construída junto ao ensino e à pesquisa. É nesse consenso, refletindo sobre os desafios da atividade de extensão universitária, que se coloca o objetivo deste capítulo: analisar a produção cientifica em Extensão Universitária, proveniente das publicações nacionais de teses, dissertações e periódicos, no período de 2007 a 2016. A pesquisa se baseia nas informações indexadas ao banco de dados da Coordenação de Aperfeiçoamento de Pessoal de Nível Superior (CAPES), mais especificamente ao Portal de Periódicos e ao Portal de Teses e Dissertações. 
Essa reflexão se mostra fundamental para evidenciar a necessidade de estudos acerca da extensão universitária, indo além da perspectiva da dinamização da extensão, mas a analisando como o espaço de produção e de reprodução do conhecimento, haja vista que a extensão universitária, enquanto atividade acadêmica, deve ser colocada "[...] ao lado do ensino e da pesquisa, na cadeia de produção e difusão do conhecimento" (NOGUEIRA, 2005, p. 11). A afirmação de Nogueira (2005) aponta para uma extensão universitária construída em um espaço em que o elemento fundante é o diálogo entre conhecimentos, e sua função se operacionaliza na instrumentalização de práticas, com o propósito de difundir os resultados consolidados no ensino e na pesquisa.

A contribuição deste estudo consiste em apresentar o processo de disseminação da comunicação científica proveniente das teses, das dissertações e dos artigos que enfatizam a temática Extensão Universitária. Ressalta-se, de acordo com Araújo e Alvarenga (2011), que, ao se realizar levantamentos, mapeamentos e análises críticas sobre um determinando tema, permite-se a compreensão da configuração da área. A bibliometria é uma ferramenta que propicia apontar resultados que podem estimular a produção de novas pesquisas, suscitar as tendências de investigação, bem como os estudos que podem ser replicados ou até mesmo evitados.

O propósito de empreender esse estudo se justifica pelo fato de não ter sido localizada, até o presente momento, nenhuma pesquisa que se proponha a investigar, mapear e analisar, especificamente, a produção científica sobre o tema Extensão Universitária. Castro (2004) cita que os trabalhos sobre extensão universitária se concentram, em sua maioria, no processo de construção histórica da extensão e sua inserção dentro da universidade como uma terceira função. Acrescenta-se, ainda, que são poucos os estudos que buscam investigar a prática dessas ações e sua contribuição para a consolidação de um campo de conhecimento (CASTRO, 2004).

Com a finalidade de responder ao objetivo central da pesquisa, o referencial teórico enfatiza os aspectos históricos, conceitos e principais diretrizes de institucionalização relativos ao campo da Extensão Universitária. Enfatiza-se a metodologia de análise bibliométrica utilizada, importante instrumento para delinear a apresentação dos dados. Por conseguinte, apresenta-se a análise dos dados, ilustrados em gráficos e tabelas. E, por último as conclusões da pesquisa.

\section{EXTENSÃO UNIVERSITÁRIA}

Neste capítulo, serão contextualizados os aspectos históricos da trajetória da extensão universitária e seu processo de institucionalização no Brasil. Esse estudo não tem a pretensão de se aprofundar sobre os temas elencados, o destaque se concentra nos momentos mais relevantes que subsidiam o debate sobre as diferentes perspectivas e sobre a complexidade do processo histórico-social expresso no contexto da extensão universitária.

\subsection{Aspectos históricos da Extensão Universitária: breves considerações}

Os primeiros movimentos e experiências relacionados à atividade de extensão universitária ocorreram no século XIX, na Universidade de Cambridge, na Inglaterra. Vale salientar que as atividades de extensão se concentravam em cursos, palestras e conferências associados a programas que atendiam a demandas específicas da sociedade, focadas, principalmente, em ações de desenvolvimento social (ROCHA, 2001).

A propagação dos resultados das experiências na Inglaterra fez com que a extensão universitária chegasse, também, aos Estados Unidos, atrelada ao ideal revolucionário de desenvolvimento regional, caracterizada como atividades de prestação de serviços nas áreas urbana e rural. No mais, as atividades de extensão universitária nos Estados Unidos destacavam, principalmente, a participação dos universitários em campanhas de saúde e nas atividades de teatro escolar (ROCHA, 2001). 
Nesse contexto e a partir dos modelos propostos pelas universidades da Inglaterra e dos Estados Unidos, a extensão universitária difundiu-se para outros países, entre eles os da América Latina. Sobre isso, é importante considerar que o marco da história da extensão universitária ocorreu com a repercussão do movimento estudantil ocorrido no ano de 1918, em Córdoba, na Argentina (FÁVERO, 1994).

Afirma-se que tal movimento representou a união dos estudantes das classes médias latino-americanas, inconformados com o papel da universidade. Esses estudantes elaboraram o Manifesto de Córdoba, que ficou conhecido como o Documento da Reforma Universitária, no qual se reivindicava uma universidade mais autônoma e democrática (FÁVERO, 1994).

No que diz respeito à sua operacionalidade, observou-se que o movimento dos estudantes "plantou a semente" para a construção de uma nova identidade para a universidade, com vistas a projetar a análise dos problemas e suas soluções. Portanto, foi evidenciada uma extensão universitária expressa como o eixo norteador da universidade, com a finalidade de estimular os problemas reconhecidos e sistematizados no seu entorno, buscando propor as soluções mais adequadas.

Ao se tratar da extensão universitária no contexto brasileiro, é importante destacar, de acordo com Nogueira (2001), que a primeira instituição de ensino superior no país que desenvolveu a atividade de extensão universitária foi a Universidade Popular de São Paulo, no ano de 1911. A motivação para que a comunidade acadêmica implementasse as atividades de conferências e os cursos para a população foi idealizada devido ao incômodo de grupos acadêmicos com o crescente elitismo na universidade, influenciado pelo modelo europeu.

A saber, as atividades extensionistas realizadas pela Universidade Popular de São Paulo não buscavam abordar as questões sociais, econômicas ou até mesmo políticas, essas atividades se caracterizaram como uma forma que a universidade encontrou para enfatizar e justificar à sociedade sua existência (NOGUEIRA, 2001).

$\mathrm{Na}$ tentativa da institucionalização da extensão no contexto nacional, as Escolas Superiores de Lavras e de Viçosa se destacaram pelo modelo voltado às atividades de prestação de serviços na área rural, nesse caso, influenciado pelo modelo americano. Assim, segundo Serrano (2001), o Brasil buscou institucionalizar a extensão copiando influências inglesas e americanas, com o predomínio de cursos e da prestação de serviços.

Diante do avanço contextual da extensão, relata-se, ainda, que a extensão passou a integrar, em 1931, o Estatuto da Universidade Brasileira, quando se propõe que "[...] a extensão se fará através de cursos de extensão destinados a divulgar, em benefício coletivo, as atividades técnicas e científicas dos institutos universitários" (BRASIL, 1931, p. 155).

Observa-se que a proposta do estatuto defende a extensão como uma atividade de difusão do conhecimento produzido na universidade hegemônica e detentora do saber, ou seja, a proposta subjacente é a realização de cursos que possam transmitir o conhecimento para a sociedade.

Nesse contexto, o conceito de extensão universitária é fundamentado nas ações unidirecionais da universidade, que produz e entrega o conhecimento sem interação com o entorno, como em posição de superioridade e produzindo ações pontuais e isoladas. Pressupõe-se, assim, um distanciamento entre universidade e sociedade. A atividade de extensão passa a ter um caráter regulador, associado ao paradigma de uma universidade que é detentora do conhecimento, como uma instituição que emerge a monocultura do saber, razão pela qual a universidade passa a excluir a sociedade (SANTOS, 2005).

A década de 1960 foi de grande importância no percurso histórico e ideológico da extensão universitária. A fissura entre a universidade e a sociedade começou a ser 
discutida a partir das reflexões de Paulo Freire, que buscou apresentar à extensão universitária uma nova roupagem, na qual se propõe que o conceito de extensão possa ser substituído pelo conceito de comunicação (SERRANO, 2006).

A proposta idealizada por Paulo Freire buscava transcender o conceito de extensão, que, sob seu ponto de vista, apresenta um caráter de imposição, pouco favorável ao diálogo, de forma persuasiva, buscando um encontro entre pessoas consideradas as donas do saber - na figura dos extensionistas - e pessoas de menos saber, ou que nada sabem, que seriam as populações com quem se trabalha (SERRANO, 2006).

A análise de Paulo Freire incorpora a ressignificação do conceito de extensão, que se iniciou na década de 1960 com o Movimento de Extensão Cultural, na Universidade do Recife. Nesse viés, surge a perspectiva da "[...] extensão como via de mão dupla e como produção de conhecimento" (SERRANO, 2006, p. 9). O fato é que as concepções de Paulo Freire, apesar de não se consolidarem no cenário nacional, trouxeram novas reflexões entre o intercâmbio de saberes e a extensão, bem como entre a universidade e a sociedade. Tem-se, desse modo, a retomada da discussão sobre extensão universitária, compreendendo o conceito como um viável componente para incitar mudanças na postura da universidade e sua projeção social.

Além disso, vale salientar que as atividades da União Nacional dos Estudantes (UNE) - movimento organizado de estudantes -, com o ideário de propor uma extensão, buscava colocar o estudante em contato com a vida social da comunidade por intermédio da troca de experiências entre estudantes e profissionais de diversas áreas. Ao que parece, isso trouxe uma nova concepção de extensão, com característica assistencialista, atuando em comunidades carentes. Percebe-se, assim, que a extensão mantém o seu caráter de transmissão de conhecimentos de uma classe dominante, trazendo à tona a discussão da extensão como uma atividade de via de mão única (NOGUEIRA, 2005).

Dado esse novo olhar, na década de 1960, mais precisamente em 1966, desenvolvese, na Universidade Federal do Rio Grande do Norte, o Centro Rural Universitário de Treinamento e Ação Comunitária (CRUTAC) e, no ano de 1967, o Projeto Rondon. O projeto CRUTAC objetivava proporcionar o contato dos estudantes universitários com comunidades rurais, já o Projeto Rondon tinha como objetivo desenvolver um espaço para a execução de ações sociais em comunidades carentes (SERRANO, 2006).

Paralelamente a esse contexto, buscando a estruturação da educação superior nas universidades brasileiras, ocorreu o movimento da Reforma Universitária Brasileira, com a promulgação da Lei $n^{\circ} 5.540$, de 28 de novembro de 1968, que estabeleceu diretrizes para o funcionamento e para a organização do ensino superior. O documento faz referência à extensão, quando cita, no artigo 40, que as atividades de extensão "[...] proporcionarão aos seus corpos discentes oportunidades de participação em programas de melhoria das condições de vida da comunidade e no processo geral de desenvolvimento" (NOGUEIRA, 2005).

Para Nogueira (2001), a Reforma Universitária foi uma iniciativa direcionada pelo governo com a pretensão de conter o diálogo mais próximo entre docentes, discentes e comunidades. Surge, nessa perspectiva, uma extensão universitária dotada de caráter político, buscando o controle e o ajustamento social, ideais fomentados na ditadura militar. Tavares (1997, p. 89) comenta que o objetivo da reforma era

\footnotetext{
[...] contornar a mobilização social direta, tentando esvaziar a representatividade das entidades da sociedade civil, deslocando, assim, o embate político, próprio de uma sociedade democrática, para o terreno técnico dos especialistas, cuja representatividade eraconferidapelo próprio governo e não pelos segmentos organizados da sociedade a quem se tentavaminimizar.
}

Acrescenta-se, ainda, que tais atividades buscavamimpetrar à extensão universitária um caráter assistencialista, tratando a extensão de forma isolada das outras atividades, 
em que a universidade é a unidade transmissora de conhecimento a receptores ávidos pelo conhecimento elaborado (SERRANO, 2006). A mesma perspectiva é argumentada por Sousa (2000, p. 55-56) ao citar que o governo "[...] assume o papel de coordenador único de toda e qualquer atividade extensionista, não abandonando, porém, a mesma concepção assistencialista [...] de extensão como prestação de serviço, dirigida às comunidades carentes."

A efervescência das discussões sobre a extensão universitária e, principalmente, sobre seus novos conceitos e perspectivas deu-se a partir da década de 1980, com a criação do Fórum Nacional de Pró-Reitores de Extensão das Universidades Públicas Brasileiras (FORPROEX), que instituiu o Plano Nacional de Extensão Universitária. Na próxima seção, será apresentada a contribuição da consolidação do Fórum no processo de fortalecimento e de integração da extensão universitária brasileira.

\subsection{A institucionalização da Extensão Universitária brasileira}

A extensão universitária, ao longo de sua historicidade, passou por várias concepções, matrizes e diretrizes conceituais. A atividade de extensão universitária já foi vislumbrada como cursos, atividades assistenciais e atividades de prestação de serviços filantrópicos. Todavia, foi a partir da necessidade de repensar a forma de atuação da extensão, tendo em vista sua forma isolada e descontextualizada do fazer acadêmico e com o propósito de ressignificar e de construir uma nova identidade para a atividade de extensão, é que foi criado, no ano de 1987, o Fórum Nacional de PróReitores de Extensão das Universidades Públicas Brasileiras (FORPROEX, 2012).

O fórum foi um marco para o desenvolvimento da extensão universitária, principalmente no que se refere à sistematização, à estruturação e à organização das ações da extensão universitária. O compromisso do fórum ficou centrado na modalidade de constituir uma referência para debater os objetivos e os desafios no âmbito da extensão universitária.

Além disso, o fórum definiu a extensão como:

[...] o processo educativo, cultural e científico que articula o Ensino e a Pesquisa de forma indissociável e viabiliza a relação transformadora entre universidade e sociedade. A Extensão é uma via de mão dupla, com trânsito assegurado à comunidade acadêmica, que encontrará, na sociedade, a oportunidade de elaboração da práxis de um conhecimento acadêmico. No retorno à Universidade, docentes e discentes trarão um aprendizado que, submetido à reflexão teórica, será acrescido àquele conhecimento. Esse fluxo, que estabelece a troca de saberes sistematizados, acadêmico e popular, terá como consequência: a produção do conhecimento resultante do confronto com a realidade brasileira e regional; a democratização do conhecimento acadêmico; e a participação efetiva da comunidade na atuação da Universidade. Além de instrumentalizadora desse processo dialético de teoria/prática, a Extensão é um trabalho interdisciplinar que favorece a visão integrada do social. (FORPROEX, 1987, p. 11).

A extensão universitária ganha uma nova dimensão com o FORPROEX. Partindo do princípio constitucional da indissociabilidade entre ensino, pesquisa e extensão, o objetivo do fórum foi tecer reflexões, definições, diretrizes e políticas para a extensão, tendo como base o compromisso da universidade frente aos problemas sociais.

Em consonância com as propostas do FORPROEX e visando operacionalizar a interlocução entre universidade e sociedade, além de assegurar mudanças na forma de fazer extensão, ocorreu, no ano de 1999, a institucionalização do Plano Nacional de Extensão Universitária. A proposta do plano expõe que "[...] do assistencialismo passouse ao questionamento das ações desenvolvidas pela extensão; de função inerente à universidade, a extensão começou a ser percebida como um processo que articula o ensino e a pesquisa [...]" (FORPROEX, 2000, p. 3). 
De fato, o Plano Nacional de Extensão Universitária fez com que se repensasse o conceito de extensão a partir da formulação de uma concepção fundamentada no caráter dialógico, com base em uma universidade que não busca somente transmitir conhecimento, mas produzi-lo na forma de interlocução com a sociedade, orientando o processo em que a universidade interage, socializa e articula o ensino e a pesquisa, com a finalidade de transformação da sociedade (SERRANO, 2006).

Para Tavares (1997, p. 15), a nova concepção de extensão “[...] nega o velho sentido de transmissão, messianismo e invasão cultural que norteia a relação entre universidade e sociedade [...]" e busca novos espaços, novas concepções e metodologias. O autor observa, ainda, que a nova concepção de extensão proporciona uma ampliação de sua perspectiva, portanto ela deixa de ser considerada uma atividade separada do ensino e da pesquisa e passa a ser colocada como uma atividade que também é o ensino e a pesquisa, em um movimento de ação-reflexão-ação.

A partir dessa nova proposta da extensão e com ampla colaboração do FORPROEX, novos progressos foram sendo implementados, com destaque ao Programa de Apoio à Extensão Universitária (PROEXT), criado pela Secretaria de Educação Superior, em 2003. O programa foi criado visando apoiar as universidades estaduais no desenvolvimento de ações de extensão que contribuam para a implementação e para o impacto de políticas, de modo a potencializar e a ampliar patamares de qualidade das ações propostas, projetando a natureza delas e a missão da universidade pública, dirigindo recursos para atividades específicas dos projetos (FORPROEX, 2012).

Ampliando o debate, Nogueira (2005) cita que a consolidação da extensão como uma práxis democrática e sistematizada pelas trocas de saberes ocorreu somente em meados de 2005, quando o Projeto Rondon foi relançado, com parceria entre o Ministério da Educação, as Forças Armadas, os governos estaduais, os governos municipais, a Associação Nacional dos Estudantes, as Organizações Não-Governamentais e a Sociedade Civil. Nessa nova fase do projeto, o destaque foi sua atuação transdisciplinar e interdisciplinar, mas o caráter do voluntariado permaneceu, uma vez que o projeto se empenha em envolver os universitários na organização e na implantação de atividades voluntárias em comunidades carentes (NOGUEIRA, 2005).

No que concerne aos avanços conceituais da extensão, observa-se que, no decorrer do primeiro decênio do fórum, ocorreu a busca por consolidar a base para o fortalecimento e para a institucionalização da extensão. Entre as principais questões destacam-se: a definição de diretrizes e política de ação; o caráter interdisciplinar da ação extensionista; a necessidade da institucionalização da extensão; o reconhecimento da importância entre a troca de saberes (saber acadêmico e saber popular); a necessidade de financiamento para a extensão (FÁVERO, 1994).

Vale ressaltar que, influenciada pelas deliberações dos fóruns, a concepção de extensão universitária se voltou para a construção de princípios norteadores, associada aos processos de transformações, estruturadas por fatores endógenos e exógenos, os quais superaram a forma inicial proposta no século $X X$, orientando, desse modo, a atividade de extensão no contexto universitário (NOGUEIRA, 2001).

Sob a lógica da ressignificação da extensão, compreende-se que o cerne encontra-se no compartilhamento de conhecimentos e de produtos entre universidadesociedade e na contribuição para práticas sociais com sustentação dialógica (SANTOS, 2005). Todavia, apesar dos esforços, "[...] a extensão continua sendo a forma como a universidade transmite às comunidades seu ensino e o resultado de sua pesquisa, de forma isolada [...], não se percebe a troca de saberes entre a universidade e a sociedade, esta é vista como mera receptora" (NOGUEIRA, 2005, p. 23).

Dessa forma, cabe expor que, mesmo com uma concepção instaurada, o desafio atual é com relação à sua aplicabilidade, isso porque a extensão universitária só se tornará consistente e qualificada quando for articulada com o ensino e com a pesquisa, promovendo um espaço democrático e aberto à população. Articular o ensino, a 
pesquisa e a extensão, atribuindo valores equivalentes, deve ser o eixo norteador da universidade (SERRANO, 2006).

$\mathrm{Na}$ esteira desse significativo avanço, a conceituação sobre extensão universitária aponta que, apesar de não existir uma única concepção nem a existência de uma coerência sobre sua função e sua práxis pedagógica, a extensão universitária se legitimou como um "[...] instrumento que vai possibilitar a democratização do conhecimento produzido e ensinado na universidade e atender às demandas mais urgentes da população" (NOGUEIRA, 2005, p. 11).

Por outro lado, "[...] ela se constitui em uma forma privilegiada, por meio da qual a universidade avalia e submete à avaliação da sociedade o conhecimento que produz, pelo confronto com situações concretas" (NOGUEIRA, 2001, p. 57). Assim, buscando conhecer a produção científica em Extensão Universitária, a próxima seção apresenta os procedimentos metodológicos utilizados para alcançar os objetivos do estudo.

\section{PROCEDIMENTOS METODOLÓGICOS}

O estudo se caracteriza pelo caráter exploratório-descritivo, já que se busca uma descrição dos dados e se está particularmente interessado na compreensão da dinâmica de operacionalização. Nesse enfoque, o procedimento para a condução dessa pesquisa foi estabelecido pela análise bibliométrica.

A análise bibliométrica busca realçar dados quantitativos de um determinado grupo de portfólio bibliográfico (artigos, teses e dissertações) mediante a contagem de documentos (ARAÚJO; ALVARENGA, 2011). Adicionalmente, esse processo objetiva o mapeamento de informações relacionadas à produção científica, de forma a quantificar sua disseminação, orientando rumos e novas premissas de pesquisas de uma determinada área do conhecimento.

Definiram-se como critérios de seleção da produção científica indexada no banco de dados da Coordenação de Aperfeiçoamento de Pessoal de Nível Superior (CAPES), mais especificamente, o Portal de Periódicos e o Portal de Teses e Dissertações. As buscas nas bases de dados ocorreram nos meses de setembro a novembro de 2016 . A opção pela análise da produção científica a partir das informações apresentadas por artigos, teses e dissertações indexados em um repositório nacional se baseia na concepção de que esse banco de dados é uma fonte segura e confiável para se conhecer a produção científica produzida no país (MELLO, 2013).

Assim, para estabelecer a amostra do estudo, utilizou-se a seleção da produção nacional. Neste estudo, entende-se que mapear a representatividade da produção nacional conduzirá a uma análise mais consolidada sobre o contexto da extensão universitária brasileira, apresentando o ranking das universidades, dos programas, dos periódicos científicos e dos autores.

Optou-se pelo uso da expressão "Extensão Universitária", mais os termos equivalentes identificados por "Ações de Extensão Universitária", "Atividades de Extensão Universitária", "Programas de Extensão Universitária", apurando o uso dessas expressões nos títulos ou nas palavras-chave, sem delimitação de áreas de conhecimento. O adjetivo "universitária" também foi substituído por "acadêmica" nas etapas de busca. Convém citar que tais adjetivos estiveram presentes em todas as buscas pelo fato de existirem expressões como "extensão rural" e "extensão agrícola", desenvolvidas por órgãos governamentais.

O recorte temporal foi definido pelo período compreendido entre junho de 2007 e julho de 2016, ou seja, um recorte temporal de 10 anos. O recorte temporal fixado justifica-se por considerar que o período de uma década, apresenta uma organização consistente da produção científica em torno do tema delimitado. 
Além disso, a coleta de dados se desenvolveu por meio da pesquisa documental que, de acordo com Creswell (2010), possibilita que o pesquisador acesse os dados de forma mais precisa, com evidências escritas relevantes sobre a pesquisa.

A coleta de dados foi realizada em duas fases. Na primeira fase, foram identificados os artigos sobre o tema Extensão Universitária. A coleta das informações nas bases de dados do Portal de Periódicos da CAPES, ao ser aplicado o filtro "revisado por pares", resultou em um total de 227 artigos completos e, considerando somente a produção científica nacional, a busca apresentou um total de 91 artigos. Com base nessas informações, o passo seguinte foi realizar a leitura dos títulos e dos resumos dos artigos. Nessa fase, excluíram-se os artigos repetidos em mais de uma base de dados e os que, após a leitura, não se enquadravam na temática pesquisada, totalizando 76 artigos completos que integraram o banco de dados do portfólio.

Para tanto, foram analisadas as seguintes informações contidas nos artigos: ano, universidade de origem do primeiro autor, periódico de veiculação e título. No que concerne às principais bases de dados dos artigos integrantes da análise, destacam-se as seguintes: OneFile, Scopus (Elsevier), Directoryof Open Access Journals (DOAJ), SciELO (CrossRef), SciELO Brazil (Scientific Electronic Library Online), MEDLINE/ PubMed e Web of Science.

Outra investigação ilustrada nesse estudo, e que torna-se um elemento complementar a investigação bibliométrica, é a análise de redes de coautoria. $O$ monitoramento das redes de coautoria, busca compreender as ligações e interações entre os autores e suas instituições de ensino. Nesse caso, utilizou-se especificamente para a análise dos artigos científicos.

O conceito de rede social no campo da pesquisa científica, traz a importância da cooperação e associação de grupos de pesquisa, compreendendo que o conhecimento científico é construído socialmente. Tal procedimento, justifica-se no fato de que quanto maior as ligações sociais, mais sólidas tornam-se as estruturas sociais.

Para apresentar a produção científica sobre "Extensão Universitária" gerada pela pós-graduação brasileira, a segunda fase dessa etapa concentrou-se na análise das teses e dissertações. Inicialmente, o banco de dados da CAPES apresentou um total de 535 teses e dissertações; posteriormente, após leitura dos títulos para alinhamento com o tema, foi acusado um total de 177 publicações, sendo 139 dissertações e 38 teses.

É importante destacar que foram apurados o número de publicações por ano, o delineamento metodológico, os temas e enfoques das pesquisas, o número de publicações por instituição, a produtividade por autores e redes de cooperação, o número de publicações e a relevância dos periódicos, além dos programas de pós-graduação que apresentaram dois ou mais trabalhos defendidos sobre o tema delimitado. Para agrupar as informações dos artigos, das teses e das dissertações, foi utilizado o editor de planilhas da Microsoft Office Excel. Na próxima seção apresenta-se a análise dos dados.

\section{APRESENTAÇÃO E ANÁLISE DOS DADOS DA BIBLIOMETRIA}

Esta seção abordará as informações relativas aos 253 registros analisados e que deram origem ao portfólio bibliográfico, composto por 76 artigos, 139 dissertações e 38 teses. No gráfico 1, são apresentadas as informações relativas aos estudos quanto à quantificação: 
Gráfico 1 - Quantificação da produção científica sobre extensão universitária (2007 a 2016)

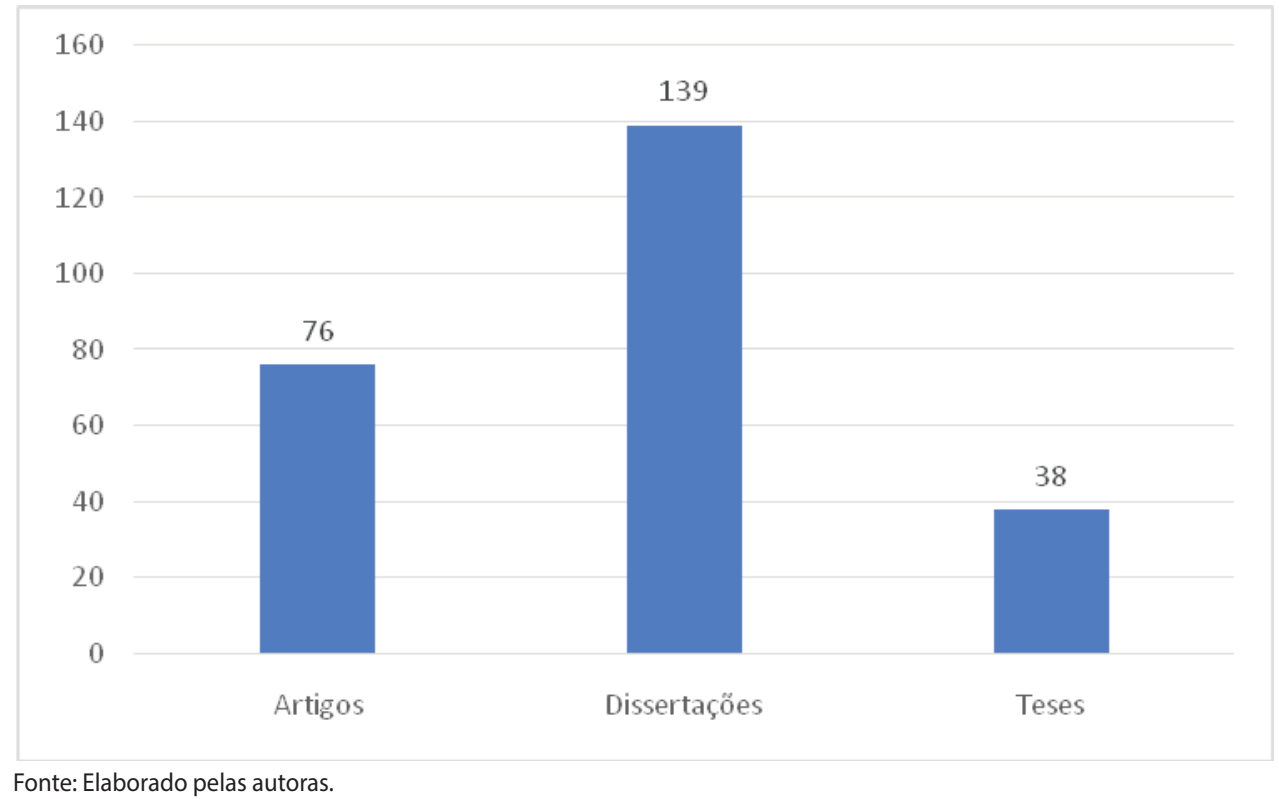

De acordo com o gráfico 1, a produção científica sobre extensão universitária se encontra representada, de forma predominante, por dissertações, com 139 registros, seguida dos artigos, 76 registros e, por último, pelas teses, 38 registros. Outra questão observada é o número maior de dissertações em relação ao número de teses, que se justifica devido ao tempo necessário para a publicação das teses e ao número reduzido de cursos de pós-graduação em nível de doutorado existentes no Brasil.

O segundo dado analisado ilustra a consolidação do número de publicações por ano com base no recorte longitudinal determinado, como pode ser visualizado no gráfico 2:

Gráfico 2 - Número de publicações por ano

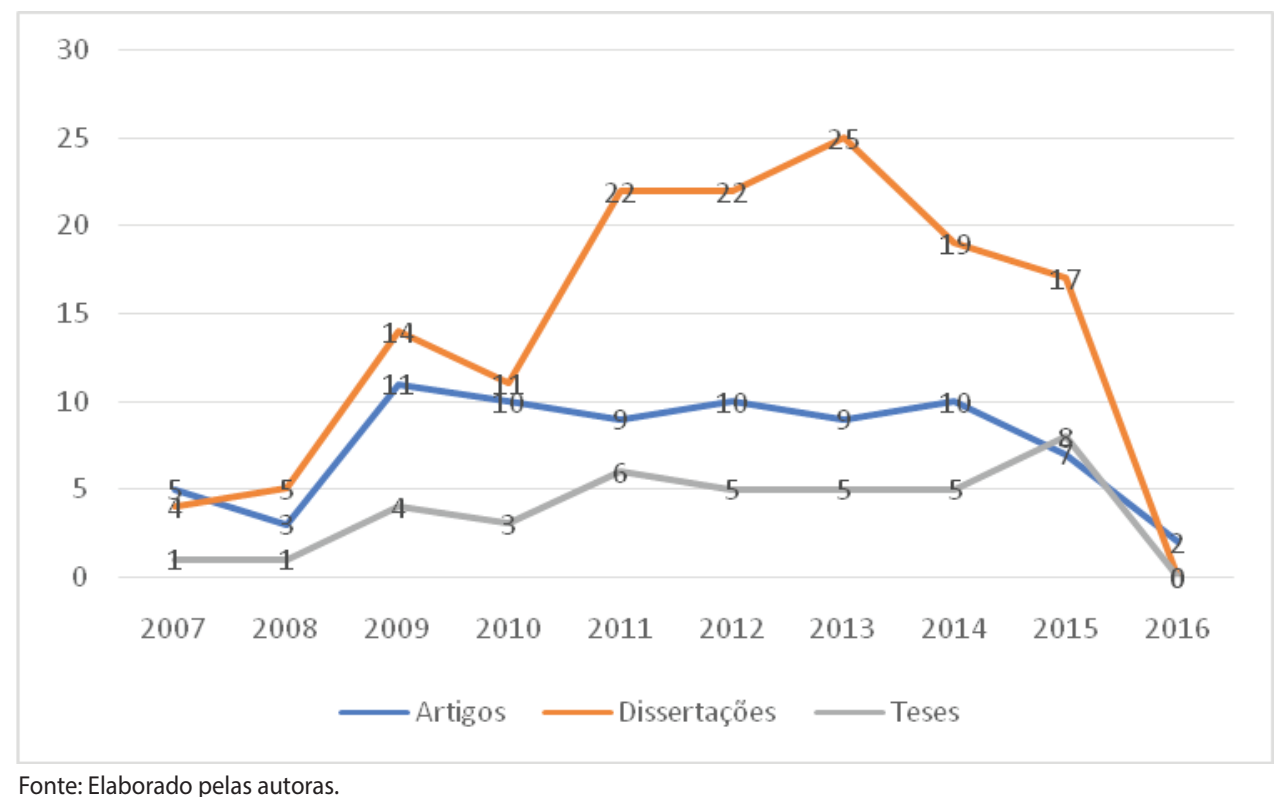

Ao analisar o panorama das defesas das dissertações e das teses sobre extensão universitária nos últimos dez anos, observa-se que o volume de publicações apresentou um crescimento maior a partir do ano de 2009, com uma maior quantificação entre o período de 2011 a 2015. Porém, os dados expressam os apontamentos de Incrocci e Andrade (2018, p. 198), que destacam que "[...] o primeiro edital aberto de fomento à prática extensionista nas universidades brasileiras teve seu resultado divulgado em 
2009 [...]"; antes desse período, o financiamento das ações de extensão "[...] não era realizado via edital, mas por cadastro de projetos no Ministério da Educação."

É oportuno salientar que, a partir de 2015, observou-se uma queda com relação ao número de publicações. O estudo de Incrocci e Andrade (2018) aborda claramente essa questão ao apontar que os recursos disponibilizados pelo governo federal tiveram uma queda significativa entre os anos de 2015 e 2016, devido à "[...] crise econômica e de contenção de gastos públicos [...]" (INCROCCl; ANDRADE, 2018, p. 198).

Somou-se a isso o fato de que, em 2016, também há uma queda, conforme dados do gráfico 2 , devido ao período de realização da pesquisa, compreendida entre o primeiro semestre de 2007 ao primeiro semestre de 2016. Nota-se, entretanto, uma linha clara, que permitiu, nesse período, que a extensão universitária ampliasse seu espaço e, consequentemente, novos âmbitos e contextos no campo da produção do conhecimento científico.

Além do número de publicações por ano, analisou-se a perspectiva do delineamento metodológico mais frequente na amostra estudada. $\mathrm{O}$ gráfico 3 apresenta a distribuição metodológica do estudo:

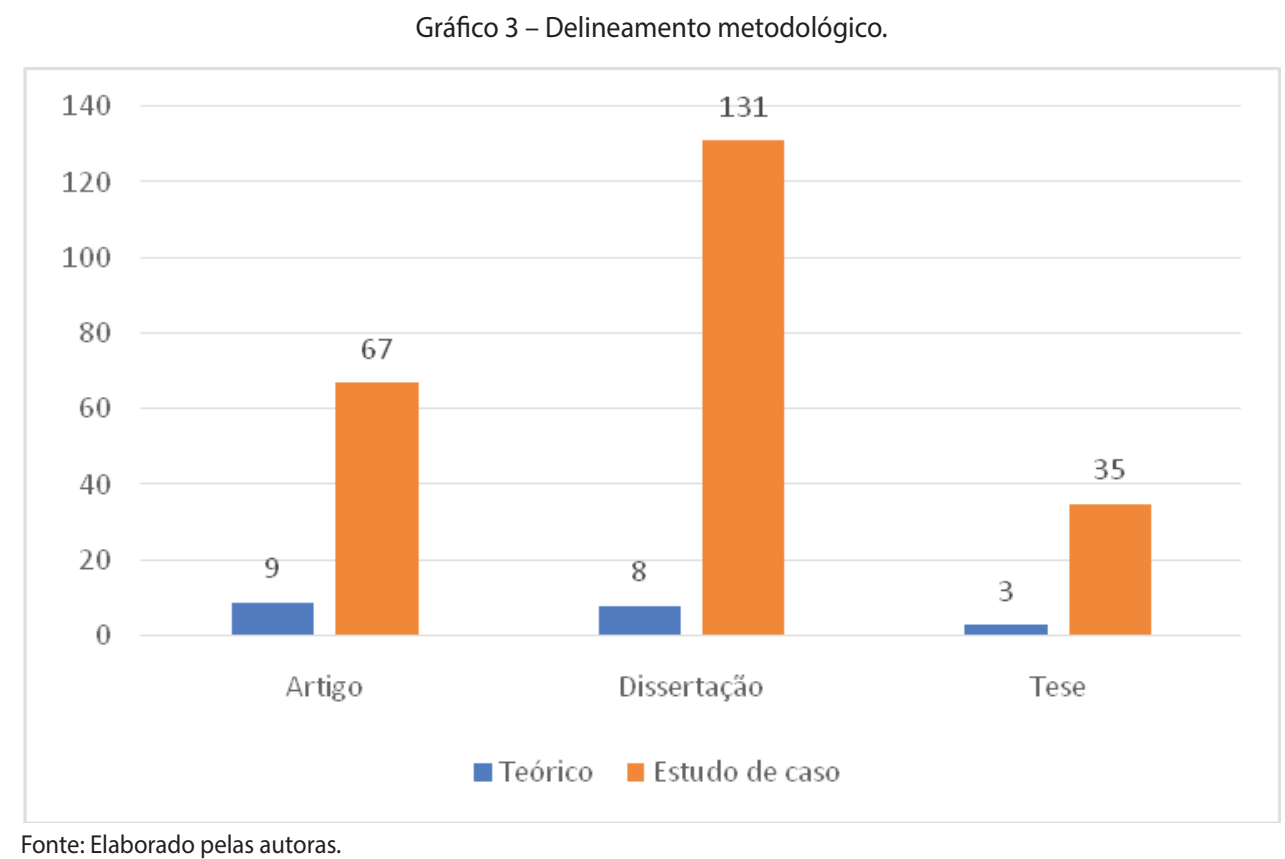

Dos 253 trabalhos analisados, 233 podem ser enquadrados como pesquisas de natureza empírica, classificadas como estudo de caso, apresentando um total de $92 \%$ dos trabalhos analisados. Ressalta-se que os artigos vinculados à categoria de estudo de caso exploraram os relatos de experiência, que são, de uma forma ampla, a descrição das ações e seus resultados. Os relatos de experiência são, em sua maioria, a modalidade metodológica mais utilizada, devido ao fato de constituírem uma forma de divulgar os resultados, corroborando uma análise crítica sobre as ações de extensão.

No contexto da abordagem metodológica sobre a extensão universitária, destaca-se a abordagem qualitativa. A predominância da abordagem qualitativa pode ser justificada pelo fato de os estudos se concentrarem nos relatos de experiências, apresentando informações provenientes da análise de documentos, de entrevistas e/ou de questionários com os sujeitos envolvidos nos projetos.

A categoria de estudos teóricos apresentou somente $8 \%$ dos trabalhos, o que equivale a 20 produções científicas. Os estudos teóricos são classificados como aqueles que apresentam discussão teórica, em que o objeto de estudo é a extensão universitária, não sendo vinculados a resultados específicos ou a ações de extensão. 
Ressalta-se, ainda, que a grande maioria dos estudos de caso encontrados teve como lócus de estudo os projetos desenvolvidos junto às comunidades, perfazendo um total de mais de $90 \%$ das publicações. Em contrapartida, os trabalhos teóricos foram realizados abordando aspectos conceituais e normativos sobre a temática da extensão universitária. Procedeu-se, também, a verificação das técnicas mais utilizadas para coleta dos dados, identificando a hegemonia de questionários e de entrevistas.

Ademais, foi possível traçar e classificar os estudos analisados por agrupamentos temáticos com base nas oito classificações delimitadas pelo Fórum de Pró-Reitores de Extensão das Universidades Públicas Brasileiras (FORPROEX), a saber: Comunicação; Cultura; Direitos humanos e justiça; Educação; Meio ambiente; Saúde; Tecnologia e produção; Trabalho. Convém enfatizar que as áreas temáticas foram criadas para facilitar a sistematização dos estudos e dos relatórios sobre a produção em caráter nacional, o que justifica a apresentação e a categorização que serão apresentadas no gráfico 4:

Gráfico 4 - Classificação por áreas temáticas.

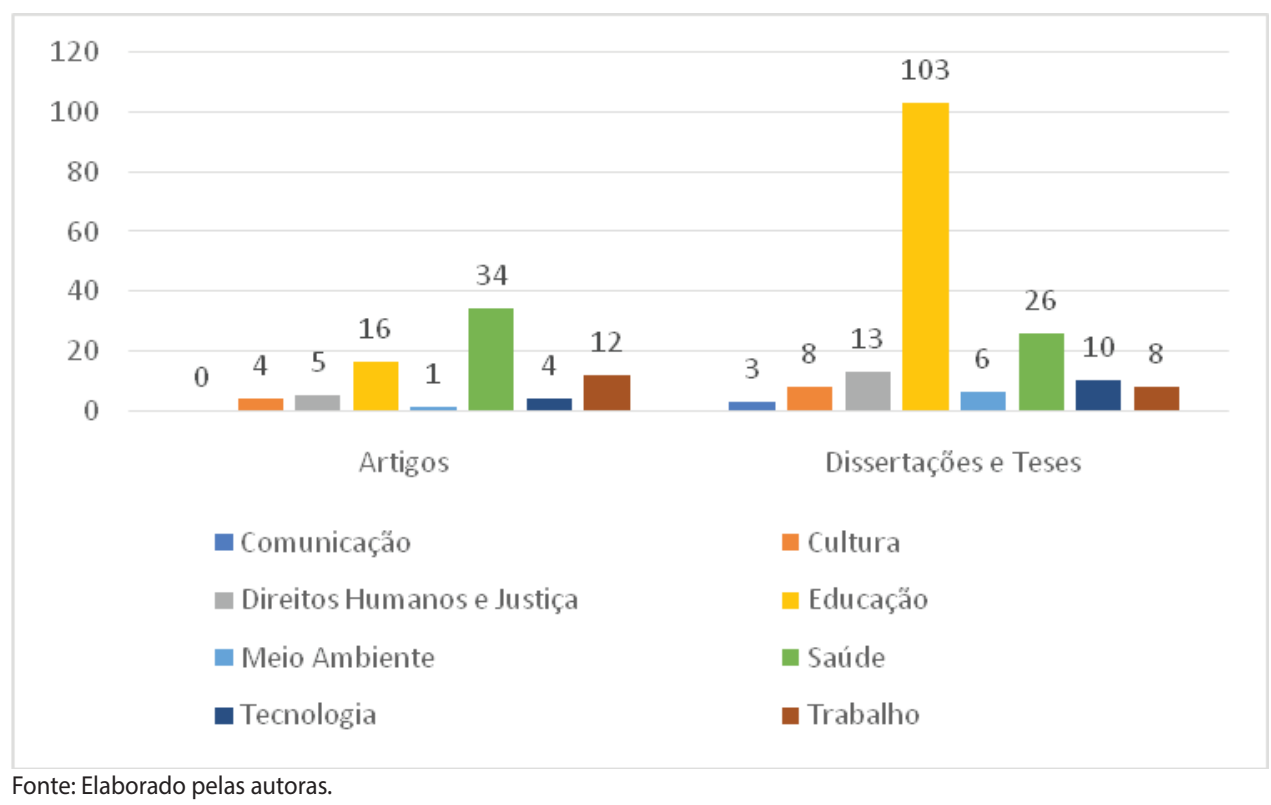

A área temática com maior destaque é da Educação, com 119 trabalhos, o que equivale a $47 \%$ do total analisado. Em seguida, vem a área da Saúde, com 60 trabalhos, o que equivale a $24 \%$ dos trabalhos analisados. A diversidade de enfoques da pesquisa se justifica pelo fato de que vários campos do conhecimento realizam extensão universitária. No entanto, as áreas de educação e de saúde são as que aparecem com um maior aprofundamento dos estudos.

Tais aspectos são sustentados pelos autores Incrocci e Andrade (2018), ao citarem que as linhas temáticas que mais absorvem recursos nos editais são as áreas de educação e de saúde. Diante disso, é notório que o fortalecimento e a legitimação da extensão universitária estão atrelados às linhas temáticas dispostas nos editais de Programa de Extensão Universitária. Enquanto isso, a ampliação de novas linhas temáticas nos respectivos editais está relacionada à incorporação de problemas e de assuntos de destaque no cenário nacional ao campo acadêmico (INCROCCl; ANDRADE, 2018).

Outro ponto de observação diz respeito às áreas de menor representatividade nos enfoques extensionistas, tais como "[...] meio ambiente, ciência e tecnologia (C\&T) e políticas públicas/direito/gestão [...]" (INCROCCI; ANDRADE, 2018, p. 203), que passaram a ganhar mais espaço na dimensão da extensão universitária após o ano de 2014. Diante disso, o que se entende com base na análise aqui referenciada é que esses enfoques ainda não apresentam resultados quantitativos expressivos, devido à sua recente integração nos tópicos extensionistas. 
Considera-se, também, que a análise das temáticas é um fator preponderante em estudos bibliométricos por proporcionar um panorama sobre a produção na área de extensão universitária. A frequência dos temas das publicações e a quantidade de publicações nos artigos (A) e nas teses de dissertações (T/D) se encontram na tabela 1:

Tabela 1 - Enfoques de pesquisa em Extensão Universitária.

\begin{tabular}{l|c|c|l|c|c}
\hline Enfoques de pesquisa & A & T/D & Enfoques de pesquisa & A & T/D \\
\hline Saúde coletiva & 27 & 20 & Atenção à terceira idade & 2 & 3 \\
Formação de estudantes & 8 & 21 & Gestão de projetos & 3 & 2 \\
Institucionalização da extensão & 0 & 25 & Desenvolvimento Regional & 0 & 4 \\
Formação docente & 5 & 17 & Direitos Humanos & 0 & 4 \\
Avaliação de projetos de extensão & 1 & 15 & Sexualidade & 4 & 0 \\
Formação cultural & 4 & 8 & Educação Infantil & 0 & 4 \\
Políticas de extensão & 0 & 11 & Esporte & 1 & 3 \\
Assessoria e prática jurídica & 3 & 5 & Gestão do conhecimento & 0 & 3 \\
Economia Solidária & 4 & 3 & Tecnologias sociais & 3 & 0 \\
Meio ambiente & 1 & 6 & Educação de jovens e adultos & 2 & 1 \\
Educação popular & 5 & 1 & Gestão social & 0 & 2 \\
Responsabilidade social & 2 & 4 & Formação política & 0 & 2 \\
Política pública educacional & 0 & 5 & Gestão da extensão universitária & 0 & 2 \\
Desenvolvimento local & 1 & 4 & Transferência de tecnologia & 0 & 2 \\
& & & & & 0 \\
\hline
\end{tabular}

Fonte: Elaborada pelas autoras.

De acordo com a tabela 1, observou-se que a Saúde coletiva foi o enfoque mais abordado nas publicações, 47 no total (artigos, teses/dissertações). Ainda pela ordem de maior incidência, prevaleceram, ocupando o segundo lugar, publicações relacionadas à Formação de estudantes.

A análise isolada dos artigos sugere que $40 \%$ deles concentram a ênfase de estudo no enfoque Saúde coletiva, enquanto apenas $11,5 \%$ das teses e das dissertações acentuaram o enfoque Formação de estudantes. Os dados constatados sugerem que a predominância do enfoque Saúde coletiva nos artigos se justifica pelo predomínio de pesquisadores vinculados aos departamentos de saúde; já o predomínio dos enfoques Formação de estudantes e Formação docente nas teses e nas dissertações se deve a uma maior concentração de programas de Pós-graduação em Educação (informações corroboradas na tabela 4).

A próxima análise busca identificar as universidades de origem dos autores das publicações que integram o portfólio bibliográfico (no caso de artigo, a contagem foi realizada com base no primeiro autor). Na tabela 2, pode ser observado o ranking das universidades que mais publicaram, de acordo com a somatória do número de artigos, dissertações e teses. Nesse aspecto, destacam-se as universidades com três ou mais publicações na soma de artigos, teses e dissertações:

Tabela 2 - Publicações por instituição sobre Extensão Universitária

\begin{tabular}{l|c|c}
\hline \multicolumn{1}{|c|}{ Instituição } & Artigos & $\begin{array}{c}\text { Teses/ } \\
\text { Dissertações }\end{array}$ \\
\hline Universidade de São Paulo - USP & 11 & 8 \\
\hline Universidade Federal de Santa Catarina - UFSC & 5 & 7 \\
\hline Universidade Federal da Paraiba - UFPB & 4 & 6 \\
\hline Universidade Federal do Rio Grande do Sul - FURG & 2 & 8 \\
\hline Universidade Federal da Bahia - UFBA & 2 & 9 \\
\hline Universidade do Estado do Rio de Janeiro - UERJ & 3 & 6 \\
\hline Universidade Estadual Paulista - UNESP & 3 & 6 \\
\hline Universidade Federal de Minas Gerais - UFMG & 0 & 9 \\
\hline Universidade Federal do Rio de Janeiro - UFRJ & 0 & 8 \\
\hline Universidade Federal de São Carlos - UFSCAR & 2 & 4 \\
\hline Universidade do Vale do Itajaí - UNIVALI & 0 & 5 \\
\hline
\end{tabular}




\begin{tabular}{l|l|l}
\hline Universidade Federal de Pernambuco - UFPE & 0 & 5 \\
\hline Universidade Federal de São Paulo - UNIFESP & 3 & 2 \\
\hline Universidade Federal Fluminense - UFF & 3 & 2 \\
\hline Universidade Estadual de Campinas - UNICAMP & 2 & 3 \\
\hline Universidade Católica de Brasília - UCB & 2 & 2 \\
\hline Universidade Federal de Viçosa - UFV & 0 & 4 \\
\hline Universidade Federal do Paraná - UFPR & 0 & 4 \\
\hline Pontifícia Universidade Católica de São Paulo - PUC/SP & 0 & 3 \\
\hline Universidade Católica de Santos - UNISANTOS & 0 & 3 \\
\hline Universidade Federal de Santa Maria - UFSM & 3 & 0 \\
\hline Universidade Federal do Rio Grande do Norte - UFRN & 3 & 0 \\
\hline Universidade Federal Rural de Pernambuco - UFRPE & 3 & \\
\hline Universidade Metodista de São Paulo - UMESP & 3 & \\
\hline Pontifícia Universidade Católica de Minas Gerais - PUC/MG & 3 & 0 \\
\hline
\end{tabular}

Fonte: Elaborada pelas autoras.

Conforme a tabela 2, nota-se que a posição central das universidades que pesquisam sobre o tema Extensão Universitária se encontra ocupada pela Universidade de São Paulo (USP), com uma representação de 11 artigos no portfólio bibliográfico e 8 incidências de teses/dissertações.

A representatividade da USP e de sua rede de pesquisadores pode ser reforçada pelo gráfico 5 (a seguir), o qual apresenta que os autores mais produtivos são vinculados a essa instituição.

É possível perceber que, das 25 universidades mais profícuas com relação ao tema Extensão Universitária, 12 são da região Sudeste (USP, UNESP, UERJ, UFMG, UNISANTOS, UFRJ, UFSCAR, UNIFESP, UFV, UMESP, UFF, PUC/MG), 5 estão concentradas na região Sul (UFSC, FURG, UFSM, UNIVALI, e UFPR), 5 são da região Nordeste (UFPB, UFBA, UFPE, UFRN, e UFRPE), 1 é da região Centro-Oeste (UCB) e nenhuma na região Norte do país.

$\mathrm{Na}$ sequência da análise bibliométrica, realizou-se o mapeamento dos autores mais evidenciados, ou seja, os que apresentaram uma maior produção científica, conforme pode ser visualizado no gráfico 5. Para essa análise utilizou-se a contagem dos autores, com foco somente nos artigos, haja vista as relações de coautorias que os artigos proporcionam.

Gráfico 5 - Produtividade por autores dos artigos sobre o tema Extensão Universitária.

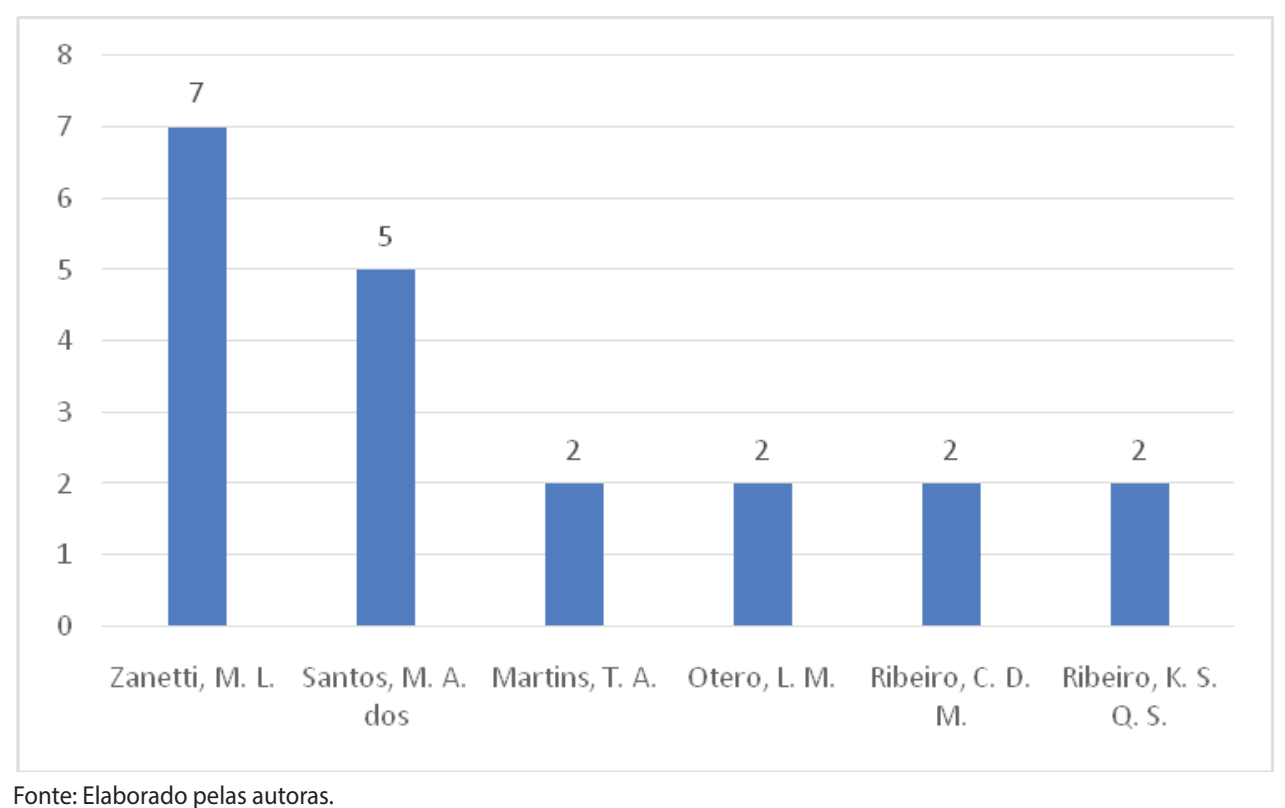

Fonte: Elaborado pelas autoras. 
Em linhas gerais, no tocante à produtividade, o destaque foi atribuído à autora Maria Lúcia Zanetti, com sete artigos publicados, seguida pelo autor Manoel Antônio dos Santos, com cinco artigos. Destacam-se, também, os autores com duas publicações: Tatiane Aparecida Martins, Liudmila Miyar Otero, Carlos Dimas Martins Ribeiro e Kátia Suely Queiroz Silva Ribeiro.

É interessante notar que os autores Maria Lúcia Zanetti, Manoel Antônio dos Santos, Tatiane Aparecida Martins e Liudmila Miyar Otero estão vinculados à Escola de Enfermagem da Universidade de São Paulo (USP). Logo, os autores mais produtivos concentram a totalidade de suas pesquisas sobre a temática da Saúde coletiva. Essa análise justifica o motivo pelo qual, entre os onze artigos publicados pela USP, sete estão relacionados à temática Saúde coletiva.

Os autores Carlos Dimas Martins Ribeiro e Kátia Suely Queiroz Silva Ribeiro possuem vínculo, respectivamente, com a Universidade Federal Fluminense (UFF) e com a Universidade Federal da Paraíba (UFPB), e estão vinculados aos programas de Saúde coletiva. Observa-se uma configuração muito interessante a partir dessa análise, que é um predomínio de pesquisadores ligados a um mesmo campo científico, nesse caso, o campo da saúde.

Os dados demonstram que os cinco primeiros autores listados no gráfico 5 são os que mais trabalham na elaboração de artigos em regime de cooperação, ou seja, com três ou mais cooperadores. Apenas a autora Kátia Suely Queiroz Silva Ribeiro possui uma publicação individual e outra publicação com apenas uma cooperação.

Aanálise revelou que, ao se comparar em quais periódicos os autores mais prolíficos pesquisaram, o destaque foi atribuído à autora Maria Lúcia Zanetti, que possui quatro artigos publicados na Revista Latino-Americana de Enfermagem. Desse modo, todas as produções sobre a temática analisada neste estudo e publicadas no periódico Revista Latino-Americana de Enfermagem têm Maria Lúcia Zanetti como um dos autores.

Outra investigação ilustrada neste estudo e que se torna um elemento complementar para a investigação bibliométrica é a análise de redes de coautoria, cujo monitoramento busca compreender as ligações e as interações entre os autores e suas instituições de ensino. Nesse caso, foram utilizados para a análise os artigos científicos.

O número de autores em um artigo evidencia as redes de parcerias. A colaboração entre os autores conduz a uma melhor articulação e à consolidação de um determinado campo científico e, por consequência, ocorre o fortalecimento de grupos de trabalho. Com isso, a geração de novos conhecimentos é condicionada ao desenvolvimento e ao crescimento da produção científica.

Dessa maneira, observa-se que a rede gerada pelos pesquisadores Maria Lúcia Zanetti e Manoel Antônio dos Santos abrange três periódicos: Revista Latino-Americana de Enfermagem, Acta Paulista de Enfermagem e Revista Brasileira de Enfermagem. Com relação à Kátia Suely Queiroz Silva Ribeiro, averiguou-se que a autora está vinculada a dois periódicos, mas com menos redes de coautores. Esses dados estão sintetizados na figura 1. 

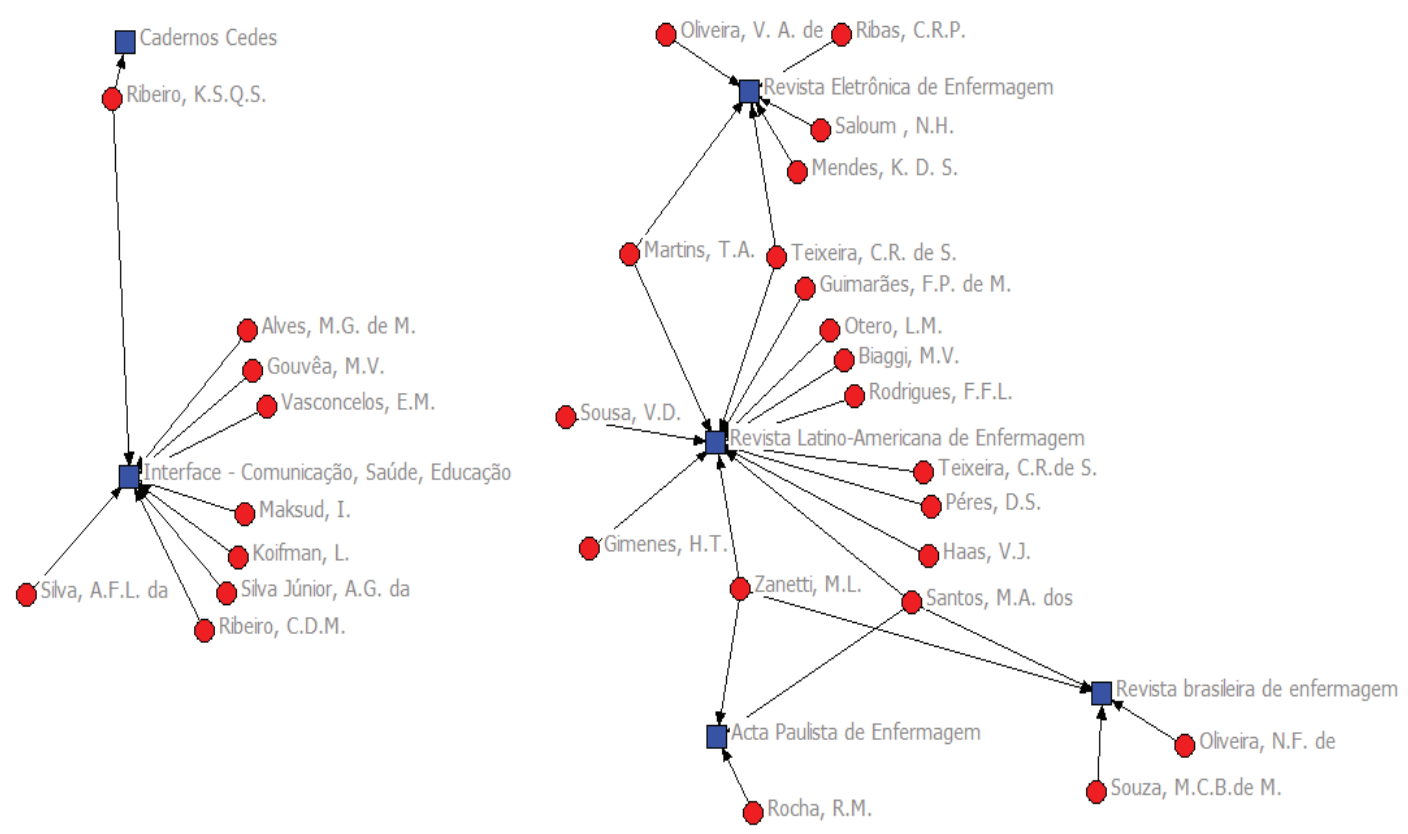

Fonte: Elaborada pelas autoras.

Constata-se que os pesquisadores da extensão universitária possuem relações movidas por reciprocidade e confiança, pois são um grupo de trabalho que estuda/estudou e/ou trabalha/trabalhou na mesma universidade, ou seja, mantém relações próximas e por um período prolongado, o que propicia uma consistência das ações do grupo. É possível, assim, pontuar que essas características são importantes para consolidar a produção científica, bem como para fortalecer e manter redes de pesquisadores.

Sobre a análise das redes de pesquisadores, especificamente, observa-se que as atividades são realizadas em equipe. Contudo, o corpus profissional é limitado aos profissionais da área da saúde. Diante disso, pode-se inferir que a ampliação das relações entre os autores poderia conduzir a uma maior diversidade profissional e seria uma forma de favorecer a geração de novos conhecimentos, de experiências e até mesmo de metodologias nas atividades de extensão. A análise das redes dos pesquisadores de extensão permite avaliar que a formação de grupos de pesquisadores é um fator determinante para o crescimento da produção científica da área.

O delineamento do cenário mostrado no portfólio bibliográfico apontou, inclusive, os periódicos que tiveram uma maior incidência de publicações sobre o tema. Conforme os dados expostos na tabela 3, o periódico Interface: Comunicação, Saúde e Educação apresentou mais publicações sobre a temática Extensão Universitária, com 9 publicações. Em seguida, aparecem os periódicos Ciência \& Saúde Coletiva, com 6 publicações, Revista Latino-Americana de Enfermagem e Revista Brasileira de Enfermagem, com 4 publicações. Esses 4 periódicos, juntos, foram responsáveis por veicular 23 artigos, o que corresponde a um total de $30 \%$ das publicações analisadas. Logo, esse núcleo de 4 periódicos responde por grande parte das publicações sobre o tema em estudo.

O estudo ainda buscou apresentar o grau de relevância dos periódicos com base no estrato Qualis CAPES. A tabela 3 destaca os periódicos, o estrato Qualis CAPES e o número de artigos publicados e que integram o portfólio bibliográfico: 
Tabela 3 - Número de publicações e relevância dos periódicos.

\begin{tabular}{c|c|c}
\hline Periódicos & Qualis & No de publicações \\
\hline Interface: Comunicação, Saúde e Educação & A2 & 9 \\
\hline Ciência \& Saúde Coletiva & A2 & 6 \\
\hline Revista Latino-Americana de Enfermagem & A1 & 4 \\
\hline Revista Brasileira de Enfermagem & A2 & 3 \\
\hline Cadernos CEDES & A1 & 3 \\
\hline Revista Meta: Avaliação & B2 & 2 \\
\hline Revista Gestão Universitária na América Latina - GUAL & B1 & 2 \\
\hline Barbarói & B1 & 2 \\
\hline ETD: Educação Temática Digital & A1 & 2 \\
\hline Revista Escola de Enfermagem da USP & A2 & 2 \\
\hline Revista Digital de Biblioteconomia e Ciência da Informação & B1 & 2 \\
\hline Psicologia \& Sociedade & A2 & 2 \\
\hline Saúde e Sociedade & A2 & \\
\hline
\end{tabular}

Fonte: Elaborada pelas autoras.

Os dados expostos na tabela 3 demonstram que as publicações estão concentradas em periódicos com alto grau de relevância no estrato Qualis CAPES. Basta ver que nove entre os treze periódicos com duas ou mais publicações estão classificados no estrato A. A tabela 3 aponta, ademais, a predominância de periódicos relacionados à área de Saúde/Enfermagem, o que pode ser explicado pelo alto número de artigos com publicações sobre a temática Saúde coletiva.

A tabela 4 expõe, por sua vez, a síntese dos programas aos quais as teses e as dissertações publicadas estão vinculadas e o número de publicações por programas. Ressalta-se que o estudo apontou um total de 85 programas. Na tabela, podem ser visualizados os 21 programas que apresentaram dois ou mais trabalhos defendidos sobre a temática Extensão Universitária:

Tabela 4 - Programas com dois ou mais trabalhos defendidos sobre Extensão Universitária.

\begin{tabular}{l|c|l|c}
\hline \multicolumn{1}{c|}{ Programas } & Quant. & \multicolumn{1}{|c}{ Programas } & Quant. \\
\hline Mestrado em Educação & 37 & Mestrado em Desenvolvimento Regional & 3 \\
Doutorado em Educação & 16 & Mestrado Profissional em Adm. Universitária & 2 \\
Mestrado em Administração & 8 & Mestrado em Tecnologia & 2 \\
Mestrado Profissional em Gestão de Políticas Públicas & 5 & Mestrado em Engenharia e Gestão do Conhecimento & 2 \\
Mestrado em Serviço Social & 5 & Mestrado em Engenharia de Produção & 2 \\
Mestrado Profissional em Gestão Pública para o & 4 & Mestrado em Educação Física & 2 \\
Desenvolvimento do Nordeste & 4 & Mestrado em Des. Regional e Meio Ambiente & 2 \\
Mestrado em Saúde Coletiva & 4 & Mestrado em Ciências da Informação & 2 \\
Mestrado em Direito & 3 & Doutorado em Música & 2 \\
Mestrado em Extensão Rural e Des. Local & 3 & Doutorado em Administração & 2 \\
Mestrado em Enfermagem & & & \\
Mestrado em Estudos Interdisciplinares sobre a & 3 & & \\
Universidade & &
\end{tabular}

Fonte: Elaborada pelas autoras.

$\mathrm{Na}$ tabela, então, verificou-se um dado expressivo, pois, de um total de 139 dissertações, 37 , ou seja, $27 \%$, estão concentradas nos programas de Mestrado em Educação.

Com relação ao programa de Doutorado, o resultado apontou que o programa de Doutorado em Educação apresentou a maior incidência de trabalhos defendidos, 43\% 
das teses defendidas no período, ou seja, 16 das 38 teses que compõem o portfólio bibliográfico são da área da educação. Como se pode notar, com relação ao universo de 177 teses e dissertações que tratam do tema Extensão Universitária, os programas de pós-graduação que mais publicaram foram os programas de Mestrado e de Doutorado em Educação.

\section{CONCLUSÃO}

Este estudo foi desenvolvido com o objetivo de analisar a produção científica em Extensão Universitária, proveniente das publicações nacionais de teses, dissertações e periódicos, no período de 2007 a 2016. A fim de alcançar o objetivo proposto, foi utilizado o desenho metodológico da análise bibliométrica, buscando identificar o número de publicações por ano, o delineamento metodológico, os temas e os enfoques das pesquisas.

Também foram pesquisados aspectos relativos ao número de publicações por instituição, produtividade por autores e redes de cooperação, número de publicações e relevância dos periódicos, procedendo-se a análise sobre os programas de pósgraduação que mais pesquisam sobre o tema. A análise conjunta indica que as pesquisas sobre o tema Extensão Universitária apresentaram uma acentuada tendência de crescimento, principalmente a partir do ano de 2009. A maior parte das pesquisas se concentra em estudos sobre a temática da saúde e da educação.

Especificamente sobre os artigos, foi observado que o periódico Interface: Comunicação, Saúde e Educação veiculou um maior número de artigos sobre o tema, seguido pelos periódicos Ciência\& Saúde Coletiva, Revista Latino-Americana de Enfermagem e Revista Brasileira de Enfermagem.

No entanto, pode-se mencionar que o cenário da produção científica nacional sobre extensão universitária ainda é pouco encontrado em publicações de periódicos. Isso se deve ao fato de que esses estudos são publicados, em sua grande maioria, em eventos específicos sobre extensão universitária, tanto para socializar mais facilmente os resultados das pesquisas como devido ao rigor metodológico que os periódicos exigem.

No tocante às publicações com foco em teses e em dissertações, verificou-se que os programas mais produtivos são os programas de Mestrado e de Doutorado em Educação. É notório apontar que as escolhas temáticas retratam, majoritariamente, as linhas de pesquisa dos programas de pós-graduação. Assim, uma análise sobre as linhas de pesquisa dos cursos de Mestrado e de Doutorado, apesar de não ser o foco de pesquisas bibliométricas, poderia auxiliar na constatação desse apontamento.

Ainstituição que apresentou uma maior influência no cenário de pesquisa analisado foi a Universidade de São Paulo (USP), tanto no panorama de artigos como nas teses e dissertações. Destaca-se que foi essa mesma instituição que apresentou o maior número de laços na análise da rede social, além do fato de que os dois autores mais prolíficos sobre o tema, Maria Lúcia Zanetti e Manoel Antônio dos Santos, também estão vinculados à USP.

Quanto à abordagem metodológica sobre a produção científica nacional em extensão universitária, foi evidenciado o predomínio do estudo de caso na corrente empírica. Essa constatação se deve ao fato de que os estudos sobre extensão universitária apresentam os resultados empíricos de suas ações.

A análise bibliométrica também traz um dado interessante: as áreas temáticas com menos publicações são a de Meio Ambiente e a de Comunicação. Tais dados são relevantes por conta das múltiplas discussões e dos interesses científicos nessas duas áreas. É nesse contexto que emerge a necessidade de debater o enquadramento da extensão universitária com ênfase nessas áreas temáticas. Com base nessa análise, 
sugerem-se novos estudos com foco no levantamento das áreas e das temáticas mais pesquisadas.

Todavia, depreende-se que os dados apresentados, resultantes das análises de artigos, teses e dissertações no banco de dados da CAPES, podem contribuir substancialmente para direcionar pesquisas sobre extensão universitária, buscando novas subáreas e temáticas a serem exploradas. Além disso, estudos podem ser realizados com base em outras fontes de dados, dessa forma, ampliando o cenário da produção científica nacional.

É sabido que esses resultados foram diagnosticados devido ao período de análise, por isso uma pesquisa com os mesmos critérios de investigação seria uma sugestão de agenda futura relevante, principalmente para avaliar a tendência de áreas temáticas.

Em linhas gerais, os dados revelados nessa análise confirmam que, apesar de décadas de discussões em fóruns e círculos científicos, o campo da extensão universitária sinaliza a necessidade de ruptura com o paradigma de que o fazer extensionista é limitado a publicações em encontros da área. As pesquisas precisam ser mais disseminadas, de forma que os pesquisadores compartilhem suas lentes e se proponham a discutir alternativas e diagnósticos relativos aos diversos problemas sociais.

O conhecimento científico não existe dissociado de iniciativas de pesquisadores, os quais buscam atender a determinadas necessidades relevantes para o desenvolvimento e para a configuração da sociedade. Desse modo, é possível afirmar que o conhecimento científico é um processo historicamente construído e que reflete as condições concretas presentes nas relações sociais, econômicas e ambientais que mobilizam a sociedade. Ao fazê-lo, enfatiza a busca por condições que vislumbram minimizar as contradições e a primazia dos interesses da lógica desenvolvimentista.

Por fim, pode-se inferir que a contribuição desta pesquisa é evidenciada pelo preenchimento de lacunas relacionadas às pesquisas de mapeamento sobre o cenário da produção científica nacional na temática Extensão Universitária. Além disso, a presente pesquisa, ao realizar uma maior exploração sobre o assunto no contexto de produção científica e no aprofundamento sobre a forma que o assunto vem sendo tratado dentro das universidades brasileiras, permitiu que se percebesse a necessidade de realizar pesquisas mais representativas, de forma a valorizar o papel da extensão no campo universitário.

\section{REFERÊNCIAS}

ARAÚJO, R.F.; ALVARENGA, L. A bibliometria na pesquisa científica da pós-graduação brasileira de 1987 a 2007. Revista Eletrônica de Biblioteconomia, v. 16, n. 31, p.51-70, 2011.

BRASIL. Decreto $n^{\circ} 19.851$, de 11 de abril de 1931. Dispõe que o ensino superior no Brasil obedecerá, de preferencia, ao systema universitario, podendo ainda ser ministrado em institutos isolados, e que a organização technica e administrativa das universidades é instituida no presente Decreto, regendo-se os institutos isolados pelos respectivos regulamentos, observados os dispositivos do seguinte Estatuto das Universidades Brasileiras. Diário Official, Rio de Janeiro, 15 abr. 1931. Disponível em: <http://www2.camara.leg.br/ legin/fed/decret/1930-1939/decreto-19851-11-abril-1931-505837-publicacaooriginal1-pe.html>. Acesso em: 10 fev. 2017.

CASTRO, L. M. C. A Universidade, a extensão universitária e a produção de conhecimentos emancipadores. In. REUNIÃO ANUAL DA ANPED, 27., 2004, Caxambu-MG. Anais eletrônicos... Caxambu-MG: ANPED, 2004. Disponível em: <www.anped.org.br/ reunioes/27gt11>. Acesso em: 5 dez. 2016. 
CRESWELL, J. W. W. Projeto de pesquisa: métodos qualitativo, quantitativo e misto. 2. ed. Porto Alegre: Bookman, 2010.

FÁVERO, M. L. A. Vinte e cinco anos de Reforma Universitária. In: MOROSINI, M. C. (Org.). Universidade e Mercosul. São Paulo: Cortez, 1994.

FORPROEX. Conceito de extensão, institucionalização e financiamento. In: ENCONTRO DE PRÓ-REITORES DE EXTENSÃO DAS UNIVERSIDADES PÚBLICAS BRASILEIRAS, 1., 1987, Brasília. Documento final... Brasília: UNB, 1987. Disponível em: <https://www.ufmg.br/ proex/renex/images/documentos/1987-I-Encontro-Nacional-do-FORPROEX.pdf>. Acesso em: 3 set. 2017.

$\overline{\text { Edição }}$ atualizada.

Plano nacional de extensão universitária. Brasília, DF: Forproex; MEC; SESu, 2000. . Política nacional de extensão universitária. Manaus-AM: Forproex, 2012.

INCROCCI, L. M. de M. C.; ANDRADE, T. H. N. de. O fortalecimento da extensão no campo científico: uma análise dos editais ProExt/MEC. Revista Sociedade e Estado, v. 33, n. 1, p. 187-212, jan./abr. 2018.

MELLO, L. C. de. Análise da produção científica brasileira sobre o conhecimento tradicional. 2013. 134 f. Dissertação (Mestrado em Ciência, Tecnologia e Sociedade)- Universidade Federal de São Carlos, São Carlos, 2013.

NOGUEIRA, M. das D. P. Extensão universitária no Brasil: uma revisão conceitual. In: FARIA, D. S. de (Org.). Construção conceitual da extensão universitária na América Latina. Brasília-DF: Universidade de Brasília, 2001.

. Políticas de extensão universitária brasileira. Belo Horizonte: UFMG, 2005.

ROCHA, R. M. G. A construção do conceito de extensão universitária na América Latina. In: FARIA, D. S. de (Org.). Construção conceitual da extensão universitária na América Latina. Brasília-DF: Universidade de Brasília, 2001. p. 13-30.

SANTOS, B. de S. A Universidade no século XXI: para uma reforma democrática e emancipatória da universidade. 2. ed. São Paulo: Cortez, 2005

SERRANO, R. M. S. M. Extensão universitária: um projeto político e pedagógico em construção nas universidades públicas. Participação, Brasília: UNB, ano 5, n. 10, 2001.

. Conceitos de Extensão Universitária: um diálogo com Paulo Freire. [S.I.: s.n.], 2006.

SOUSA, A. L. L. A história da Extensão Universitária. Campinas-SP: Alínea, 2000.

TAVARES, M. das G. M. Extensão universitária: novo paradigma da universidade. Maceió: EDUFAL, 1997. 